\title{
Explanation of a Knowledge Workers Maintenance and Retention Model in Mapna Electric and Control, Engineering and Manufacturing Company (MECO)
}

\author{
Behnam Dehban ${ }^{1} \&$ Azadeh Heydari ${ }^{2}$ \\ ${ }^{1}$ Manager of Strategic Planning, Systems \& Quality, Mapna Electric and Control, Engineering and \\ Manufacturing Company, Iran \\ ${ }^{2}$ Manager of the Development of Talents \& Human Capital Development, Saman Insurance Company, Iran \\ Correspondence: Behnam Dehban, Mapna Electric and Control, Engineering and Manufacturing Company, \\ Alborz, Km 7 mallard road, Mapna Blvd, Iran. E-mail: behnam.dehban@gmail.com
}

Received: June 12, 2016

Accepted: June 28, 2016

Online Published: July 21, 2016

doi:10.5539/mas.v10n9p253

URL: http://dx.doi.org/10.5539/mas.v10n9p253

\begin{abstract}
This research aimed to investigate and explain maintenance and retention model of Knowledge workers in MECO Company in 2015. The research statistical population consisted of all Knowledge workers with working conditions in MECO Company. Based on the estimation, the number of eligible employees was determined 138 people. 102 people among these were considered as sample size using Cochran formula and simple random sampling method. Data collection methods had been both qualitative and quantitative. Effective components were extracted on the basis of statements recorded from interviewees, discussions and dialogues, principles of observations, documentation and so on. It also was measured by researcher-made questionnaire. Questionnaire reliability was calculated using Cronbach's alpha method. Its value for all variables of questionnaire was acceptable values higher than 0.7 . Similarly, the content validity was used to test the validity of the questionnaire. For this purpose the questionnaires were confirmed by relevant experts. Data obtained from the implementation of questionnaires were analyzed using SPSS software in two descriptive and inferential parts. Finally, the research results in the form of a model confirmed role of factors such as organizational structure of occupational satisfaction, communication system, evaluation and control system, organizational culture, pay and reward system, and job stress in the retention and maintenance of Knowledge workers in MECO Company.
\end{abstract}

Keywords: knowledge workers, knowledge work, communications systems, organizational culture, job stress

\section{Introduction}

In today's competitive knowledge-based economy and trade of world, development and maintenance of high-performance Knowledge workers with high potential abilities will be crucial at all levels of any organization. In other words, in the view of maintenance of Knowledge workers' discussion, market has become a place of talent exchange. This is employees that choose when and where to work and supply their talent. On the other hand, organizations should do everything in order to attract, develop, manage and maintain these employees. This is what causes global non-duplication and continuous competitive advantage for the organization (Briscoe, 2008, p.197). In fact, one of the main concerns of organizations, especially knowledge organizations is the issue of employees' desertion. Since, according to Afkhami Ardekani (2011), employees' desertion while imposing direct and indirect costs, causes transmission of capabilities to competing companies and ultimately loss of competitive advantage, so it is important and necessary to maintain and retain Knowledge workers is posed. The higher skills and capabilities of Knowledge workers, comparative advantage and effectiveness of the organization are higher. So maintenance and retention of these key employees, means Knowledge workers is very important for organizations (Taheripour, 2011). No doubt having competent and efficient Knowledge workers is one of the important and crucial issues of human resources and knowledge management. This has allocated considerable portion of experts' attention to itself in today's world. On the one hand, this issue is an approach that by accurate recognition of criteria for maintenance and retention of Knowledge workers can design their evaluating and ranking system. This system can be used for different purposes, including promotion, training, suitable job selection, job rotation, provision of a clear work and 
occupational prospect, performance improvement, and definition of job descriptions (Thanagoo, 2011).

Therefore, it seems that one of the concerns, which its solution can have a significant impact on productivity and development of any organization is how Knowledge workers' management and leadership is. This is because Knowledge workers are considered of factors causing advantage and very important for any industry, agency or country. In the current organization, Knowledge workers are turned to strong organizational assets. They create value for the organization by their activities, and have a significant role in organizations' goals achievement.

So consider this point indicates that the organization should pay special attention to the correct leadership and supply factors of occupational satisfaction, motivation factors, and maintenance and retention of these valuable assets to utilize their professional knowledge, skills and abilities in the best way. It should align objectives of these employees with its goals. In addition, due to intense competition among existing organizations in order to attract and retain these employees, they require to assign precise strategies on interaction with these employees (Hedayat \& Nazari, 2010).

The companies in which many Knowledge workers are working (like MAPNA Group and subsidiaries) due to the nature of their activities, activity and survival of each of these people is very important, because the company spends a lot of costs for these employees from employee-finding stage to recruitment, and then getting to know the work and the necessary trainings. If these people leave the company, in addition the loss of these costs and repeat it for a replacement, experiences that people acquire will be also lost (Gholipour et al., 2013).

However, MECO Company is registered in the four main areas of power plant industries, oil, gas and petrochemical industries, rail transport industries, and renewable energy (wind farms) industries to engineer, manufacture, and transfer electrical control systems' technology since 2004. The founders and directors of this company are the experienced people involved in this industry for many years. They believe that using the latest knowledge and professional tools, and belief on customer-orientation principle, customers' need is identified and the best products and services are provided to its customers. According to this company's goals and vision that intends to be paramount integrator and designer of electrical control systems by the year 1400, and accordingly, it has determined the core values for itself, including customer-orientation, innovation, excellence-seeking, responsibility, business ethics (in the form of headword of I to we) within the organization.

Considering the aforementioned, purpose of this research is to determine Knowledge workers' maintenance and retention model to deal with Knowledge workers; because, as was stated, one of the problems of current organizations and companies is high job leaving of Knowledge workers. Organizations and companies will utilize higher competitive advantages using this model. They will achieve organizational goals by better leadership of Knowledge workers and maintain and retain them.

\section{Research Literature}

To enter discussing explanation of Knowledge workers' maintenance and retention model is initially required to investigate Knowledge workers' variable in the view of definitions by different thinkers, dimensions, features, etc. But the most important thing than investigation of Knowledge workers is that the purpose of work knowledge to be specified, which is dealt in this section:

\subsection{Work Knowledge}

There are several definitions for the word of work knowledge. Some of them can be noted; according to Maier (2005) work knowledge is a creative work that solves non-structured problems that require the creation of knowledge. Also Dunning (2000) believes that work knowledge is alone as a valuable and economic competitive advantage for organizations. In fact, the main activity in the work knowledge is thinking about what value is added to work through mental activities. In fact, it seems that there are key differences between work knowledge and other works as follows:

1) The main activity in work knowledge is to think. Work knowledge creates added value for activity. It includes the activities of issues' analysis, decision making and applying the results in the other conditions.

2) Type of thought in work knowledge is not linear, step by step mental work. Knowledge workers must act in their thought creatively and non-linear.

3) Work knowledge applies knowledge to produce more knowledge. Work knowledge is beyond the mere use of knowledge and its output is creation of new knowledge.

Following Maier (2005) states that the characteristics and features of work knowledge are as following Table: 
Table 1. Characteristics and features of work knowledge (Maier, 2005)

\begin{tabular}{ll}
\hline Target & $\begin{array}{l}\text { Solving complex and structured problems and issues with large volume of variety and } \\
\text { exception }\end{array}$ \\
\hline Contents & $\begin{array}{l}\text { Creative work requires creativity, acquisition, utilization and distribution of knowledge and } \\
\text { having information and knowledge inputs and outputs. }\end{array}$ \\
Work Style & $\begin{array}{l}\text { Includes a number of specific activities such as description and extraction of experiences, } \\
\text { recording of learned things from the events, the translation of knowledge into other fields, } \\
\text { interpretation and analysis of knowledge and network with other people. }\end{array}$ \\
Individual skills & $\begin{array}{l}\text { Applying intellectual abilities and professional knowledge instead of physical abilities and } \\
\text { and abilities }\end{array}$ \\
requirement of having a high level of education, training and experiences that have led to \\
skills and expertise.
\end{tabular}

\subsection{Knowledge Workers}

It has been found in recent researches that knowledge is the only source of competitive advantage for companies in the age of knowledge-centered economy, and organizations' managers are facing with new challenges every day. One of the challenges in today's highly competitive environment is that simple employees that are replacing with information professionals called "Knowledge workers" (Hedayat Nazari, 2010).

Peter Drucker introduced the word of knowledge workers for the first time to explain the growing role of group of employees in the organization. He stated that manual employees were basic capital in the past, but today, basic investment for a developed economy is knowledge workers. They will apply what they have learned in a systematic education. In 1989, he also described knowledge workers as a people who create added value for the organization by processing existing information to create new information by which can define and solve problems. By this definition, can find that why the organization focus mostly on attracting and maintaining knowledge forces (Hedayat \& Nazari, 2010).

Davenport instead of definition by Drucker defines Knowledge Workers in a way that knowledge workers have a high degree of expertise, training or experience, and their primary objective is to engage in the creation, distribution or use of knowledge (Davenport, 2005, p. 217).

These employees are usually those who acquired knowledge from formal education to develop new required products or services and need to learn continuously. The task of Knowledge Workers is to collect develop, process, and apply information that creates profit for organization (Smith \& Rapp, 2004; Thanagoo, 2011).

Horowitz considers knowledge workers those who have high skill and education, technical education, high cognition and reasoning power, and having ability to observe, combine, and interpret data and information to make better decisions and provide better solutions for the organization (Horwitz, 2000, p. 500).

In other words, knowledge workers are employees who are responsible for the development and production of ideas and concepts rather than exclusively focus on the implementation or management of existing processes or activities of the company. Knowledge worker is a person who works on development activities or used knowledge. Knowledge workers do physical activity and usually are hired by companies to conduct innovative activities. Knowledge workers are a member of organization that uses knowledge to greater productivity and effectiveness (Thanagoo, 2011).

Finally, it can be stated that today knowledge workers are identified as a factor that increases the speed and effectiveness of knowledge creation and transfer. This would be help organization in improving performance. In addition, the organizations with qualified knowledge workers are more capable in knowledge management (Rasouli and Rashidi, 2015, p. 40). 


\section{Characteristics of Knowledge Workers}

As stated, knowledge work is a complex work. Those who are doing it require having certain abilities and skills. The importance degree of this characteristic varies in different employees. All knowledge workers must have the following characteristics:

- Having intellectual and theoretical knowledge: knowledge workers require related education in the future in order to achieve the required information to enter in a certain field of working activity. Because knowledge is always being created, these employees will need more information based on the principle of continuous learning.

- Finding and accessing information: in a time that today's information society activities depend on the knowledge that is constantly growing and changing, distribution of information between organizations has become a major problem due to the great volume of information that employees need to learn. Knowledge workers must know how to find such tools independently. Such employees need to know which sources provide information they need, and how to apply these sources to establish information successfully.

- The ability to apply information: knowledge workers apply information in order to respond to questions, solve problems and generate ideas. Non-repetitive nature of the knowledge workers' job makes the ability to apply information necessary for new positions.

- Communication skills: knowledge work requires direct communication with customers, supervisors, subordinate, and teams. Focus on the localization of services and goods to satisfy the needs and demands of customers have caused knowledge workers have a direct relationship with customers. Knowledge workers have communication skills which enable them to work together to achieve goals, make decisions and generate ideas.

- Motivation: the nature of knowledge work needs continuous growth in the form of development of skills and information. Knowledge workers should be interested in finding information, retaining this information, and applying them to carry out their works.

- Intellectual capabilities: knowledge workers must have intellectual abilities to achieve the aforementioned skills. These intellectual capabilities include cases in relation to the understanding and applying of specific information (Thanagoo, 2011).

\section{Research Background on Maintenance and Retention of Knowledge Workers}

Martin (2011) has approved role of human resources activities on the tendency to stay within the employees (Martin, 2011, p. 77). Delfgaauw \& Dur (2010) have concluded proper and appropriate management of talent in public organizations can provide the context and ground for self-regulation and motivation of employees to increase performance level and more participation. Joy liment on the important factor in maintaining and retaining employees, states that organization should be treated with employees as if all of them are director and partner.

All of them are shareholders. Directors know success because of this issue. But the greatest problem is that causes managers concern is that do not lose these talented people. Managers know that talented employees can go wherever they want. There is nothing more important than hiring talented and developed forces. This is the first and foremost thing to do (Sadoughi, 2014).

According to Shuaib (2006) proper management tools of knowledge workers with the aim to increase their efficiency include:

- Design work (teamwork)

- Having the authority and autonomy at workplace

- Loyalty to the organization

- Training and Development

- Motivation (competitive rewards, bonus packages and other Applause)

- Communication channels

- Monitoring and evaluation

- $\quad$ Balance work cycle (Shuaib, 2006)

Chew (2004) in his doctoral dissertation has found that human resources' activities affect the stay of Australian organizations' main employees. In fact, these actions provide the ground for employees' tendency to stay by influencing organizational commitment of the employees (Chew, 2004, p. 214). In this regard, Sparrwo \& Hitrop (1994), by examining the growing problems of talent shortage in most European countries, have concluded that 
in the twenty-first century, there is an increasing need to employees with a wide range of required skills and abilities to deal with unforeseen needs of organizations (Noe' Pasand Asil, Malekakhlagh, and Ashegh Hosseini Mehravani, 2013).

Inside the country Chaichi (2015) states that organizational culture; employees' organizational commitment, perceived organizational support, and occupational satisfaction affect the maintenance and retention of employees, respectively. Rasouli and Rashidi (2015) also have found that, human resources' programs, including skills development, salary and benefits, the opportunity to participate, organizational support, and procedural justice can predict the intention to stay in the organization through variables of occupational satisfaction, organizational commitment, and trust to managers. Among them organizational support has the direct effect and strongest indirect effect on knowledge workers' intention to stay.

Soheili (2014) in his research has found that organizational culture has a significant and positive impact on knowledge storage. Organizational culture has a significant and positive impact on organizational commitment. Knowledge storage has a significant positive impact on employees' retention. Organizational commitment has a significant positive impact on employee retention. But organizational culture has no impact on maintenance and retention of knowledge workers. Gholipour and colleagues (2013) also believe that there is a difference between knowledge workers and their managers about the factors influencing their stay in the organization. knowledge workers considers the variables of public trainings, independence, social protection, and payment important, while managers focus more on occupational satisfaction, payment, social protection, and justice.

Afkhami Ardekani (2011) finds that organizational culture has a positive, direct and significant impact on confidence. Trust has a significant and inverse impact on the desire to leave work. As well as trust has an intermediary role in the relationship between organizational culture and the desire to leave work. Taheripour (2011) also believes that variables of human resources' strategy and organizational culture together can predict a significant percentage of changes in knowledge workers' maintenance and retention. Finally the following Table shows the model in the discussed field:

Table 2. Factors affecting the maintenance and retention of employees

\begin{tabular}{ll}
\hline Identified Factors & Model \\
\hline $\begin{array}{l}\text { Occupational satisfaction, organizational size, alternative employment option, job } \\
\text { compatibility, occupational diversity }\end{array}$ & $\begin{array}{l}\text { March and Simon } \\
\text { model }\end{array}$ \\
$\begin{array}{l}\text { Other occupational opportunities, occupational satisfaction, cost of leaving the Mental process } \\
\text { organization }\end{array}$ & $\begin{array}{l}\text { Ali Mudai model } \\
\text { Alternative occupational options, occupational expectations }\end{array}$ \\
Stress on the employees, occupational satisfaction, occupational opportunities & $\begin{array}{l}\text { Lee and Michelle } \\
\text { model }\end{array}$ \\
occupational satisfaction, organizational commitment, occupational opportunities & Winterton model \\
Colleagues' support, justice, promotion opportunities, and commitment to job & $\begin{array}{l}\text { Price and Muller } \\
\text { model }\end{array}$ \\
\hline
\end{tabular}

Finally, with regard to the research background and literature; and the fact that MECO Company has suffered a lot of material and immaterial losses from lack of maintenance and retention of knowledge workers at various levels; and that is why has dealt with this issue as basic weakness and challenge in organizational strategic strategy document; and has decided to conduct a scientific and training research for the above subject's pathology, and providing a model and scientific strategies to solve this organizational challenge. Therefore, in this article after the research background and literature review, we aims to investigate this issue that what is an appropriate model for knowledge workers' maintenance and retention in MECO Company?

The basic ground in theoretical model of the present research is to utilize different dimensions that have been considered in the form of key factors influencing the increase in maintenance and retention of MECO Company knowledge workers. Based on the aforementioned components, in the form of a semi-structured interview, it was in disposal of 30 academic experts and experts. Based on their views, the research variables were extracted. Variables that had the most frequency were chosen. These variables constituted the main components of the operational model of the research as examined variables as follows. 
Organizational structure: knowledge workers are very annoyed of the bureaucracy and paperwork in the organization. They prefer to work in small organizations. Because they have more freedom of action, and structure is less formal in them. They considers flat and decentralized structure, a structure that has flexibility required to provide practical and intellectual works, encourages creativity and initiative, and is flexible against change as a condition for effectiveness of their work (Goman, 2000).

Occupational satisfaction: occupational satisfaction is a very important factor in occupational success. Occupational satisfaction is a factor that increases the efficiency, as well as individual satisfaction feeling. Researchers have defined occupational satisfaction from different perspectives. They believe that if a job provides the desired pleasure for the person, in this case, the person is satisfied with his job. Occupational satisfaction is an attitude that indicates how employees feel about their jobs in general or towards its different fields. Occupational satisfaction is an emotional response to occupational situation through understandable introspection. Like any other tendency, occupational satisfaction cannot be observed; its existence and quality can be inferred from the behavior of the employee or verbal speech.

Occupational satisfaction as a general feeling of the people towards their job has a direct impact on the individual, social, and organizational life. It plays a crucial role in mental and physical health. In contrast job dissatisfaction decreases work spirit, performance and endangers the physical and mental health of the personnel. In fact, it seems that occupational satisfaction refers to the positive or negative value judgment that one has of his job or his occupational position. In other words, occupational satisfaction is an attitude that indicates how people feel about their jobs in general or towards its different fields (Spector, 2000).

Communication system: Constant, open and close relationships with co-workers and managers are the basic conditions of knowledge workers; because their work is complex and interdisciplinary, and exchange of information and ideas is a key factor to run affairs. Knowledge workers expect members of the organization to make their information available to each other. They are not interested to work in an organization where secrecy is a condition for progress.

Assessment and control system: knowledge workers are worry about too much control of their managers over them and not giving them enough authority to act. They expect their managers behave them like a co-worker; and control output and added value of their work rather than direct monitoring.

Organizational culture: Organizational culture is one of the most important factors affecting the maintenance and retention of employees. An important issue is worthy and respectful behavior of director with knowledge workers. One of the most important principles to attract, maintain and retain knowledge workers is value-centric positive attitude towards them (Gholipour et al., 2013).

Payment and reward system: the payment of adequate reward to knowledge workers is very important in the situations where this issue is the most common policy of organizations to retain and maintain knowledge workers (Winterton, 2004).

Stress: Since knowledge workers in dealing with ideas and innovations may often make mistakes and fails, they should not have any concerns about the cost of these mistakes or the manager deal with their mistake. Otherwise this causes stress, and consequently feeling of unrest and anxiety of these employees. Ultimately if this does not lead to leaving job will certainly lead to mental deterioration. In this regard, based on the factors affecting retention and maintenance of knowledge workers, the research hypotheses are as follows, respectively:

- First hypothesis: Organizational structure has a role in maintenance and retention of MECO Company's knowledge workers.

- Second hypothesis: Occupational satisfaction has a role in maintenance and retention of MECO Company's knowledge workers.

- Third hypothesis: Communications system has a role in maintenance and retention of MECO Company's knowledge workers.

- Fourth hypothesis: Assessment and control system has a role in maintenance and retention of MECO Company's knowledge workers.

- Fifth hypothesis: Organizational culture has a role in maintenance and retention of MECO Company's knowledge workers.

- Sixth hypothesis: Payment and reward system has a role in maintenance and retention of MECO Company's knowledge workers.

- The seventh hypothesis: Occupational stress has a role in maintenance and retention of MECO Company's 
knowledge workers.

\section{Research Methodology}

This research in terms of purpose is applied, and in terms of method is survey - descriptive. The research statistical population had consisted of all knowledge workers in MECO Company in 2015. Since the respondents in this research must have a comprehensive and perfect view towards the subject and have knowledge work, on the other hand, more than 70\% of MECO Company' employees have education higher than bachelor's degree, questionnaires only was provided to use by knowledge workers with degree higher than bachelor's degree and work experience of above 7 years who are concerned with knowledge works.

As a result, these employees constitute statistical population of this research and their number is estimated at 138 people. Simple random sampling has been used to select samples. In simple random sampling method for determining the sample size, at first pre-sampling was conducted on the statistical population of 30 persons. Due to the standard deviation and population size (138 persons) and the value of error at 0.05 , and placement in Cochran random sampling formula, sample size was determined 102 persons. Also, because the present research is survey, and was in local territory of MAPNA Electric \& Control, Engineering \& Manufacturing (MECO), therefore it was conducted as field study. Standard questionnaires with five-item Likert scale were used to collect the data. In addition, the internal consistency of the used tools was assessed and confirmed using Cronbach's alpha coefficient according to the following Tables.

Table 3. Cronbach's alpha coefficients for research variables

\begin{tabular}{lll}
\hline Raw & Scale options & Alpha \\
\hline $\mathbf{1}$ & Organizational Structure & $\mathbf{0 . 8 0 6}$ \\
$\mathbf{2}$ & Occupational satisfaction & $\mathbf{0 . 9 1 2}$ \\
$\mathbf{3}$ & Communications system & $\mathbf{0 . 7 3 9}$ \\
$\mathbf{4}$ & Assessment and control system & $\mathbf{0 . 8 4 4}$ \\
$\mathbf{5}$ & Organizational Culture & $\mathbf{0 . 8 7 2}$ \\
$\mathbf{6}$ & Payment and reward system & $\mathbf{0 . 9 0 9}$ \\
$\mathbf{7}$ & Occupational stress & $\mathbf{0 . 7 8 2}$ \\
\hline
\end{tabular}

Also face and content validity of research tool (questionnaire) was approved by ten professors and experts.

\section{Research Findings}

To analyze the data obtained from questionnaires, Kolmogorov - Smirnov test was used before any step to assess normality or abnormality of the data.

Table 4. Test results of normality of variabl

\begin{tabular}{llll}
\hline Variable & (Significance level) & $\alpha$ (error value) & Test result \\
\hline Organizational Structure & $\mathbf{1 3 . 0}$ & 0.05 & Normal \\
Occupational satisfaction & $\mathbf{1 1 . 0}$ & 0.05 & Normal \\
Communications system & 0.14 & 0.05 & Normal \\
Assessment and control system & 0.09 & 0.05 & Normal \\
Organizational Culture & 0.09 & 0.05 & Normal \\
Payment and reward system & 0.08 & 0.05 & Normal \\
Occupational stress & 0.10 & 0.05 & Normal \\
\hline
\end{tabular}

As can be seen, distribution of all variables is normal. So single-sample t- test is used to test research hypotheses. 
Table 5. Analytical findings of hypothesis by one-sample $t$ test

\begin{tabular}{lllllll}
\hline Variable & Frequency & Average & Standard deviation & t & df & Sig. \\
\hline Organizational Structure & $\mathbf{1 0 2}$ & $\mathbf{3 . 8 3}$ & $\mathbf{0 . 6 8 8}$ & $\mathbf{1 7 . 2 8}$ & $\mathbf{1 0 1}$ & $\mathbf{0 / 0 0}$ \\
Occupational satisfaction & $\mathbf{1 0 2}$ & $\mathbf{3 . 8 0}$ & $\mathbf{0 . 6 8 9}$ & $\mathbf{1 6 . 6 7}$ & $\mathbf{1 0 1}$ & $\mathbf{0} / \mathbf{0 0}$ \\
Communications system & $\mathbf{1 0 2}$ & $\mathbf{3 . 8 5}$ & $\mathbf{0 . 6 1 5}$ & $\mathbf{1 9 . 7 9}$ & $\mathbf{1 0 1}$ & $\mathbf{0} / 00$ \\
Assessment and control system & $\mathbf{1 0 2}$ & $\mathbf{3 . 6 6}$ & $\mathbf{0 . 7 6 6}$ & $\mathbf{1 2 . 4 2}$ & $\mathbf{1 0 1}$ & $\mathbf{0} / \mathbf{0 0}$ \\
Organizational Culture & $\mathbf{1 0 2}$ & $\mathbf{3 . 8 4}$ & $\mathbf{0 . 6 3 1}$ & $\mathbf{1 9 . 0 4}$ & $\mathbf{1 0 1}$ & $\mathbf{0} / \mathbf{0 0}$ \\
Payment and reward system & $\mathbf{1 0 2}$ & $\mathbf{3 . 8 7}$ & $\mathbf{0 . 6 0 6}$ & $\mathbf{1 6 . 4 4}$ & $\mathbf{1 0 1}$ & $\mathbf{0} / \mathbf{0 0}$ \\
Occupational stress & $\mathbf{1 0 2}$ & $\mathbf{3 . 5 6}$ & $\mathbf{0 . 6 0 1}$ & $\mathbf{1 6 . 1 1}$ & $\mathbf{1 0 1}$ & $\mathbf{0} / \mathbf{0 0}$ \\
\hline
\end{tabular}

Single sample t-test results for all variables indicate that the value of $t$ is higher than standard value of 1.96. Therefore all null hypotheses are rejected here, and contrary hypothesis (research hypotheses) is confirmed.

\section{Discussion and Conclusion}

In general, today's world is full of complexities that have caused various companies to be faced with many problems in the field of growth and development. The most important of them is maintenance and retention of the employees. These problems have caused managers to be faced many challenges at all levels as planners, organizers, and leaders in the fields of human resource management. In this condition, the explanation of the employees' maintenance and retention model and especially knowledge workers can be useful to overcome the existing problems and the growth and success of companies. A model was achieved in this part after the data analysis in the present research and testing of research hypotheses. Then it has been tried to interpret the obtained results accurately and truly.

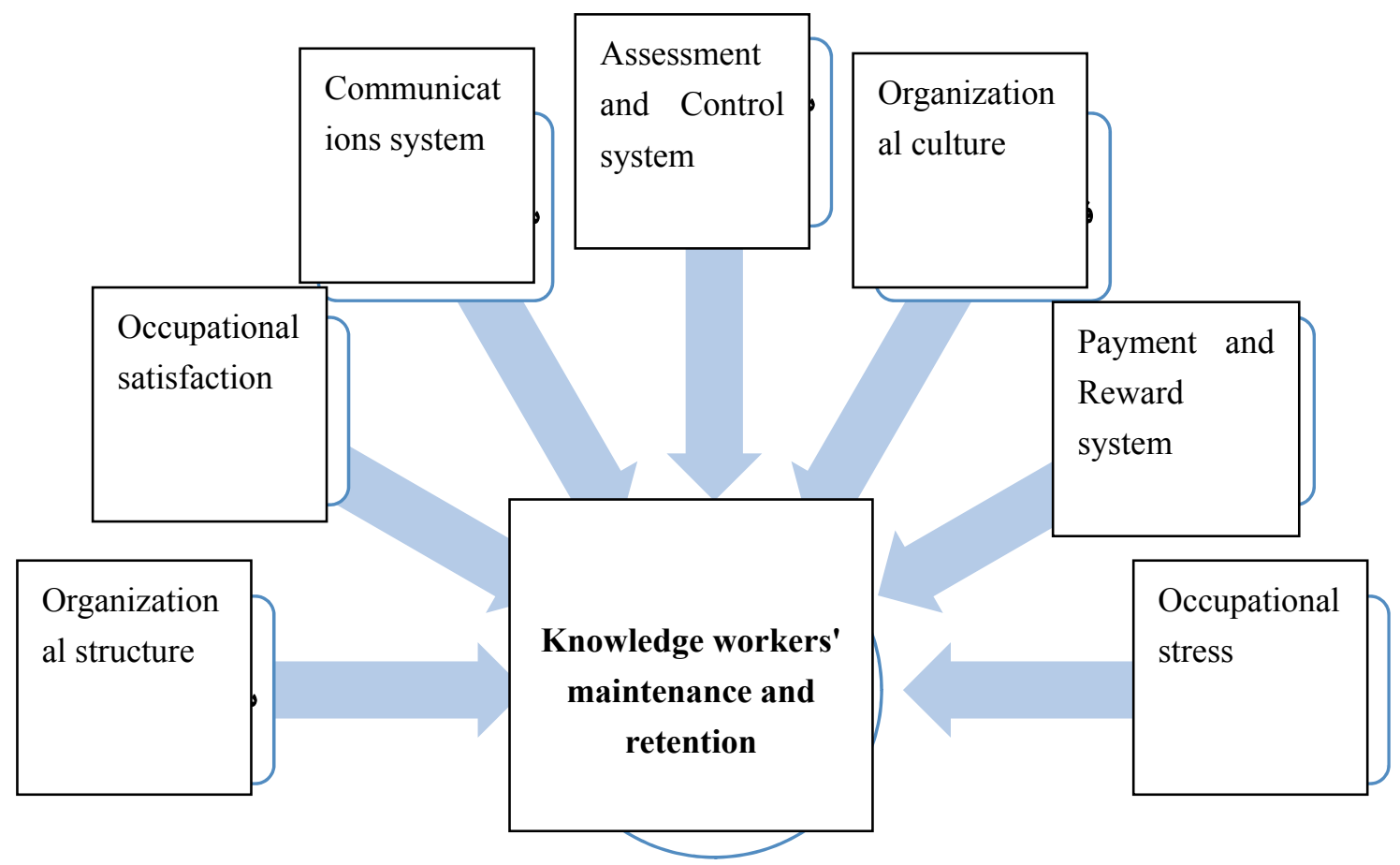

Figure 1. Ultimate model of knowledge workers' maintenance and retention

Given that knowledge workers are very annoyed of bureaucracy and paperwork in organization, and flat and decentralized structure is suitable for their practical and intellectual activities, therefore role of the organizational structure in maintenance and retention of knowledge workers is provable and defensible. Research findings by Goman (2000) are also confirmed this subject. Also, since occupational satisfaction factor that enhances 
efficiency, as well as personal satisfaction in the knowledge workers, provides the ground necessary for maintaining and retaining them. In fact, occupational satisfaction is an attitude that how the knowledge workers feel about their jobs in general and/or towards its different fields of their activities. This causes more interest and tendency in them that research findings by Spector (2000) also confirm this.

On the other hand communication system according to the fact that it facilitates the transfer of knowledge and experiences in company, and this issue is of the requirements and basic conditions for maintenance and retention of knowledge workers. For the cause that work of knowledge workers is complex and interdisciplinary staff, and the exchange of information and ideas is a key factor in promoting their activities. Employees also expect managers to control their output and added value of their work, rather than direct monitoring. They are annoyed of managers too much control them and give them not enough authority to act. This affects the decision-making of knowledge workers to stay or leave the company.

The role of organizational culture as one of the most important factors affecting the maintenance and retention of employees was also confirmed. In fact, if the culture of the organization encourages and supports knowledge workers, and there is a positive attitude to their knowledge works, there would be greater incentive in them to stay, and the necessary ground is provided for retaining knowledge workers. Paying adequate reward to knowledge workers gives them the sense that organization understands the value of their works; and the added value they bring to the organization can be seen by the senior managers.

Therefore, this system facilitates maintenance and retention of knowledge workers. Winterton (2004) has also approved this effect.

Finally, since knowledge workers may often make mistakes and fail in dealing with ideas and innovations, they should not have any concern about the costs of these mistakes and/or how the manager deals with their mistakes.

Finally, with regard to the ultimate model of this research, the following suggestions are presented in MECO Company in order to retain and maintain knowledge workers:

- It is suggested that the leader of the organization pays strategic importance to the knowledge management and respects it. So knowledge workers more realize their work's value, and the sense of being seen in organization and the necessary motivation is arised in them.

- It is suggested to promotion a learning culture that helps to retain knowledge workers.

- Supporting knowledge management processes through the human resources' programs and its strategies helps the maintenance and retention of knowledge workers.

- Also knowledge workers in organizations that have confidence in their managers, their intention to stay are increased. So organizations' managers who are concerned about retaining their knowledge workers need to appoint an effort to make trust in their organization.

Finally, the following practical suggestions are offered in order to maintain and retain knowledge workers in Electric and Control, Engineering and Manufacturing Company (MECO):

- The incentive system designed for knowledge workers is recommended as a fundamental act for MECO Company.

- Determining jobs, and strategic practitioner, and developing human resources' programs for employees who work in these jobs.

- Providing and setting work contracts for knowledge colleagues and developing discrete welfare programs.

- Determining development occupational path of knowledge workers.

- Defining certain work packages and evaluating the performance of knowledge workers through examining the output of defined work packages.

- Allocating a percentage of profits from the commercialization of new projects of knowledge workers.

\section{References}

Afkhami, A. M. (2011). Corporate trust; the Missing link of knowledge, the mediating role of trust in the relationship between culture and knowledge workers leaving job. Seventh Human Resource Development Conference Center, productivity and human resources.

Briscoe, \& Dennis (2008). Talent Management and the Global Learning Organization (pp.195).

Chaeichi, \& Airkeyvan. (2015). Check individual and organizational factors influencing the retention of employees in the company spreads eagle (Master's thesis). University anymore. 
Chew, J., \& Cheng, L. (2004). The Influence of Human Resource Management Practices on the Retention of Core Employees of Australian Organizations: An Empirical Study (Unpublished Doctoral Dissertation). Murdoch University.

Davenport, T. H. (2005). Improving Knowledge Worker Performance. MIT Sloan Management Review, 46(4), 215-235.

Delfgaauw, J., \& Robert, D. (2010). Managerial talent, motivation, and self-selection into public management. Journal of Public Economics, 94(9-10), 654-660.

Gholipour, R., Amiri, A. N., Mehdi, R., Mohammad, R., \& Zamanifar, M. (2013). Identify factors affecting shelf life of knowledge workers in the Iranian Oil Refining and Distribution Company. Journal of Management and Organizational Culture, XI(II), 161-133.

Goman, C. K. (2000). The human side of High-Tech / Lessons from the Technology Frontier. John Wiley \& Sons / Inc.

Hedayat, N., \& Faezeh (2010). A model of leadership strategies for knowledge workers (Master's thesis). Non-profit institution of higher education Virtual Farabi, Faculty of Management.

Horwitz, M. (2000). Flexible Work Practices and Human Resource Management. International Journal of Human Resource Management, 9(4).

Lee, T. W., Mitchell, T. R., Haltom, B. C., McDaniel, L., \& Hill, J. W. (1999). Theoretical development and extension of the unfolding model of voluntary turnover. Academy of Management Journal, 42, 450-462.

Maier, R. (2005). Modeling Knowledge Work for the Design of Knowledge Infrastructures. Journal of Universal Computer Science, 11(4), 429-451.

Martin, M. J. (2011). Influence of Human Resource practices on Employee Intention to Quit (Unpublished Doctoral Dissertation). Faculty of Virginia Polytechnic Institute and State University.

Nopasand, A. S. M., Malekakhlagh, E., \& Ashegh, H. M. (2013). Examine the relationship between talent management and organizational performance. Publication, Inquiry Management, (6), 51-31.

Price, J., \& Mouler (2006). Reflection on the determinants of voluntary turnover. International Journal of Manpower, 22(7), 600-624.

Rasouli, R., \& Rashid, M. (2015). Define and design a basic knowledge of the maintenance staff. Journal of Human Resource Management University of Imam Hussein (AS), 7(1), 55-39.

Sadoughi, \& Syede, Z. (2014). Identify the relationship between talent management and organizational development and job motivation and high school teachers in the first period of Education District 19 of Tehran (Master's thesis). Islamic Azad University.

Shuaib, \& Shandana (2006). Managing Knowledge Workers. Faculty Member Institute of management Sciences Peshawar (7 / B-3, Phase-V, Hayatabad, Peshawar).

Soheilifar, \& Soraya (2014). The Role of culture in the preservation of knowledge workers (Master's thesis in ISIRI). Islamic Azad University of Tehran.

Spector, P. (2000). Industrial and organizational psychology. New York, John willey and sons.

Taheripour, \& Syede, S. (2011). The relationship between HR strategy and organizational culture and preservation of knowledge workers in the enterprise Zamyad (Master's thesis). Allameh Tabatabaei University.

Thanagoo, Sh. (2011). Provides a method for assessing and ranking the knowledge workers using a fuzzy approach (Master's thesis in Case study organizations in Iran). University of Technology.

Winterton, J. (2004). A conceptual model of labour turnover and retention. Human Resource Development International, 7(3), 371-390.

\section{Copyrights}

Copyright for this article is retained by the author(s), with first publication rights granted to the journal.

This is an open-access article distributed under the terms and conditions of the Creative Commons Attribution license (http://creativecommons.org/licenses/by/3.0/). 